4-1-2021

\title{
Increasing modern contraceptive use among women in Sokoto State
}

Breakthrough RESEARCH

Follow this and additional works at: https://knowledgecommons.popcouncil.org/departments_sbsr-rh How does access to this work benefit you? Let us know!

\section{Recommended Citation}

Breakthrough RESEARCH. 2021. "Increasing modern contraceptive use among women in Sokoto State," infographic. Washington, DC: Population Council. 


\section{Increasing Modern Contraceptive Use Among Women in Solkoto State}

The Breakthrough RESEARCH project conducted a behavioral surveillance survey in September 2019 for health among women who had a pregnancy or birth in the previous two years.

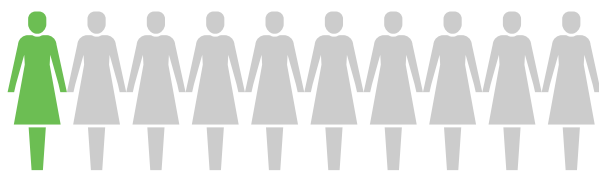

Only about 1 out of $10(\mathbf{1 2 \% )}$ women in 10 surveyed local government authorities (LGAs) of Sokoto State are currently using modern contraception.

\section{Survey Findings for Sokoto State}

The behavioral surveillance survey identified three important factors for increasing modern contraceptive use. The percentages shown below are the averages for all the LGAs sampled. These averages may differ from the median values shown on the next page.

\section{Women have ever talked with their husband or partner about whether to use a method of contraception}

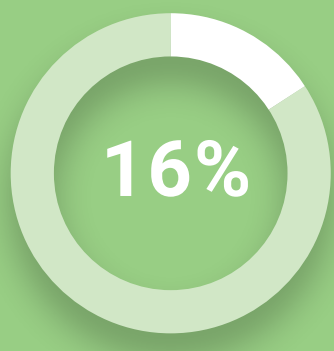

Only about 1 out of 6 women have ever talked with their husband or partner about whether to use a method of contraception.

\section{Women personally approve of using contraception for spacing births}

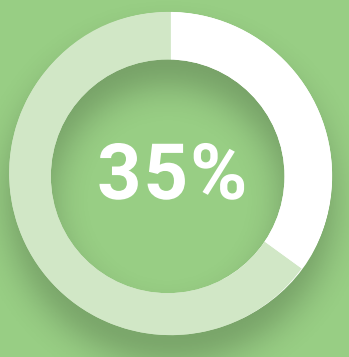

Less than 4 out of 10 women personally approve of using contraception for spacing births.

\section{Women with high knowledge ${ }^{\dagger}$} regarding family planning (FP)

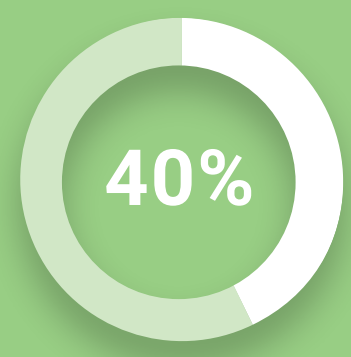

Less than half of women have high knowledge regarding FP.

${ }^{+}$High knowledge of FP is measured as knowing the benefits of FP for the woman and her children, knowing that contraceptives have limited side effects, the benefit of having childbirth after age 18 and the risks of high fertility.

\section{If these and other factors are improved further, modern contraceptive use may rise in Sokoto State.}

Survey Results by Local Government Areas in Sokoto State

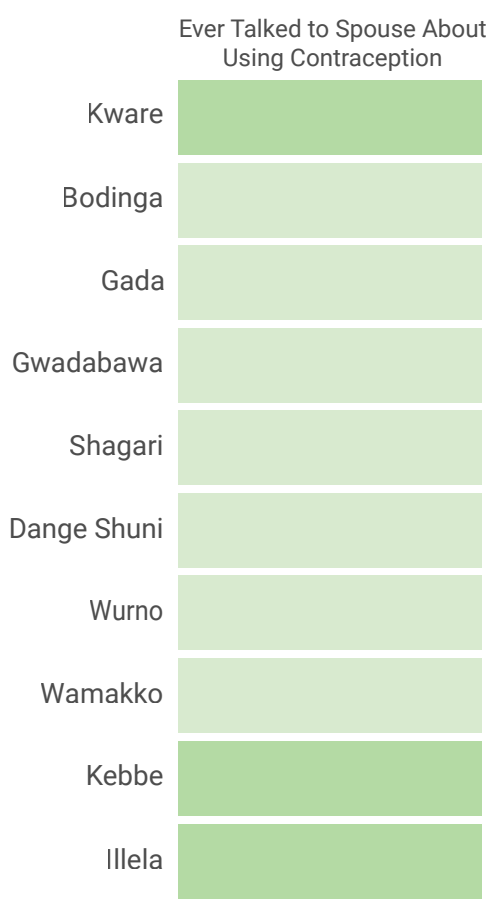

\section{Approves of Using} Contraception
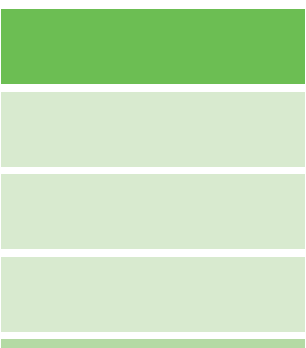

\section{I}

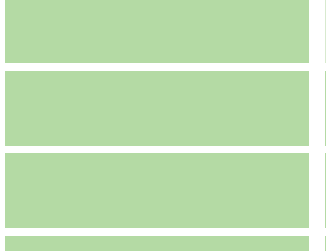

t 


\section{Increasing Modern Contraceptive Use Among Women in Sokoto State}

The Breakthrough RESEARCH project conducted a behavioral surveillance survey in September 2019 for health among women who had a pregnancy or birth in the previous two years.

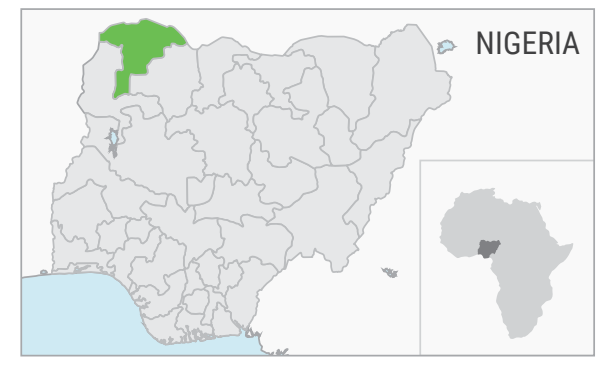

\section{Survey Findings for Sokoto State}

The behavioral surveillance survey identified three important factors for increasing current modern contraceptive use. The percentage in each box below is the median (50th percentile). Half of LGAs are below (red) and half above this value (green).

\section{Women have ever talked with their \\ husband or partner about whether to use a method of contraception}

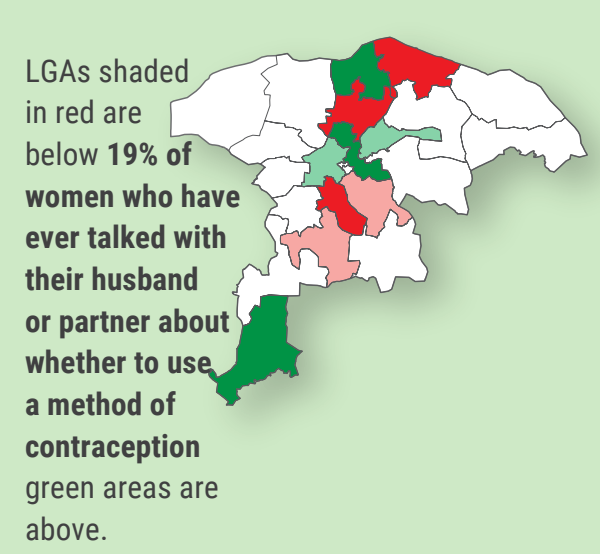

\section{Women personally approve of using contraception for spacing births}

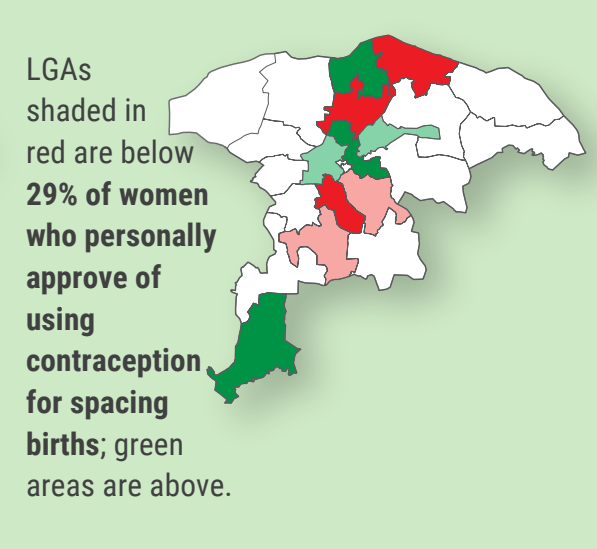

Women with high knowledge regarding FP

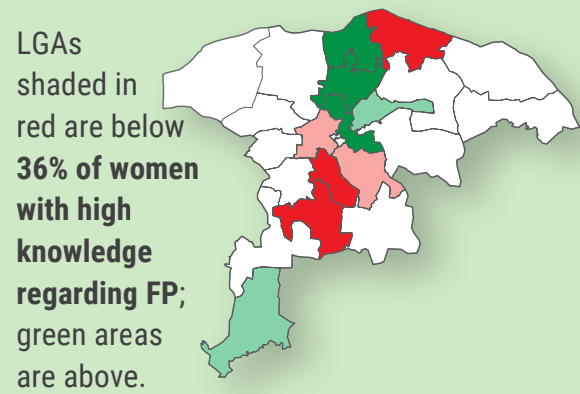

Notes: Lightly shaded areas are immediately below or above the median. Darker shaded areas are further away from the median, below the 25 th or above the 75th percentile. LGAs in white were not sampled for the survey and information is not available for these areas.

\section{How can this information be used to improve modern contraceptive use in Sokoto State?}

Discussion and inquiry into barriers and facilitators of using modern contraception may provide insights on how to enhance efforts in these areas by asking questions such as:

- What is different about the wards in LGAs in green that may explain the quality of service delivery in their health facilities? Do LGAs in green receive greater support for supplies, service quality improvement, and social mobilization?

- What is different about the communities that may explain how well an LGA is doing? Do they have stronger leaders, ward development committees, or levels of community engagement in health issues?

- What barriers are present in LGAs in red that influence the outlined factors i.e., knowledge of FP, personal approval and spousal communication, and how do these inhibit women from using modern contraception? How can these barriers be addressed by community leaders and members of the community?

- Do LGAs in green have facilitators that increase women's knowledge, approval, agency for spousal communication and their ability to use modern contraception? How can they be adopted in other areas with lower levels of modern contraceptive use?

- How can additional efforts be made or information tailored to reach communities and households in the greatest need of improving these factors related to modern contraceptive use?

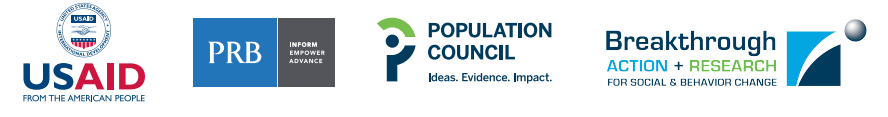

